\title{
Combined impact of healthy lifestyle factors on risk of asthma, rhinoconjunctivitis and eczema in school children: ISAAC phase III
}

\author{
Eva Morales, ${ }^{1}$ David Strachan, ${ }^{2}$ Innes Asher, ${ }^{3}$ Philippa Ellwood, ${ }^{3}$ Neil Pearce, ${ }^{4}$ \\ Luis Garcia-Marcos, ${ }^{5}$ the ISAAC phase III study group
}

\begin{abstract}
- Additional material is published online only. To view please visit the journal online (http://dx.doi.org/10.1136/ thoraxjnl-2018-212668).

${ }^{1}$ Biomedical Research Institute of Murcia (IMIB-Arrixaca), University of Murcia, Murcia, Spain

${ }^{2}$ Population Health Research Institute, St George's, University of London, London, UK ${ }^{3}$ Department of Paediatrics: Child and Youth Health, University of Auckland, Auckland, New Zealand ${ }^{4}$ Department of Medical Statistics, Faculty of Epidemiology and Population Health, London School of Hygiene and Tropical Medicine, London, UK

${ }^{5}$ Biomedical Research Institute of Murcia (IMIB-Arrixaca), University of Murcia, Murcia, Spain
\end{abstract}

\section{Correspondence to} Dr Eva Morales, IMIB-Arrixaca Biomedical Research Institute, Murcia 30120, Spain; embarto@hotmail.com

Received 1 October 2018 Revised 24 January 2019 Accepted 11 February 2019 Published Online First 21 March 2019

\begin{abstract}
Background Asthma is not the key focus of prevention strategies. A Healthy Lifestyle Index (HLI) was developed to examine the combined effect of modifiable lifestyle factors on asthma, rhinoconjunctivitis and eczema using data from the International Study of Asthma and Allergies in Childhood (ISAAC) phase III.

Methods Information on symptoms of asthma, rhinoconjunctivitis, eczema and several lifestyle factors was obtained from children aged 6-7 years through written questionnaires. The HLI combined five lifestyle factors: no parental smoking, child's adherence to Mediterranean diet, child's healthy body mass index, high physical activity and non-sedentary behaviour. The association between the $\mathrm{HLI}$ and risk of asthma, rhinoconjunctivitis and eczema was evaluated using multilevel mixed-effects logistic regression models.
\end{abstract} Findings Data of 70795 children from 37 centres in 19 countries were analysed. Each additional healthy lifestyle factor was associated with a reduced risk of current wheeze (OR $0.87,95 \% \mathrm{Cl} 0.84$ to 0.89 ), asthma ever (OR $0.89,95 \% \mathrm{Cl} 0.87$ to 0.92 ), current symptoms of rhinoconjunctivitis (OR $0.95,95 \% \mathrm{Cl} 0.92$ to 0.97 ) and current symptoms of eczema (OR 0.92, 95\% Cl 0.92 to 0.98 ). Theoretically, if associations were causal, a combination of four or five healthy lifestyle factors would result into a reduction up to $16 \%$ of asthma cases (ranging from $2.7 \%$ to $26.3 \%$ according to region of the world).

Conclusions These findings should be interpreted with caution given the limitations to infer causality from crosssectional observational data. Efficacy of interventions to improve multiple modifiable lifestyle factors to reduce the burden asthma and allergy in childhood should be assessed.

\section{INTRODUCTION}

Asthma is currently the most common chronic disease in childhood worldwide. ${ }^{1}$ Higher prevalence rates of asthma have been reported in Western countries and in those that are English speaking; however, in the last two decades, the prevalence of asthma there has changed little globally and even declined in some Western countries. ${ }^{2}$ Most people affected are in low-income and middle-income countries, ${ }^{3}$ where asthma prevalence is estimated to be increasing fastest presumably because of their progressive 'westernisation' of environmental and lifestyle factors. ${ }^{4}$

\section{Key messages}

What is the key question?

- What is the combined effect of common modifiable lifestyle factors on asthma, rhinoconjunctivitis and eczema in childhood?

What is the bottom line?

- This large worldwide multicentre crosssectional study found that with each point added to a child's healthy lifestyle index (ie, no parental smoking, child's healthy body mass index, adherence to a Mediterranean diet, physical activity and non-sedentary behaviour), the risk of current wheeze and reported asthma ever fell by $13 \%$ and $11 \%$, respectively. Theoretically, if associations were causal, adherence to a combination of four or five healthy lifestyle factors would theoretically prevent up to $16 \%$ of asthma cases.

Why read on?

- These findings should be interpreted with caution given the limitations to infer causality from cross-sectional observational data; however, results suggest that researchers should consider adapting and assessing the efficacy of public health interventions modifying multiple lifestyle factors to reduce the burden of asthma.

The aetiology of asthma remains largely unknown, but it is likely a multifactorial and heterogeneous condition, involving combined or interacting effects of non-modifiable (ie, heredity and sex) and modifiable (ie, environment and behaviour) risk factors. ${ }^{5}$ The International Study of Asthma and Allergies in Childhood (ISAAC) has revealed several modifiable parental and child lifestyle factors to be individually associated with the risk of asthma and allergy symptoms in childhood. These include secondhand tobacco smoke exposure from parental smoking, ${ }^{6}$ some specific dietary patterns (eg, Mediterranean diet and fast food), ${ }^{7-9}$ child's overweight and obesity ${ }^{10} 11$ and child's physical activity and sedentary behaviour ${ }^{11}$; which are also the focus of population-wide approaches to prevention of cardiovascular disease and cancer in adults. 
Although it would be pertinent to quantify the joint effect of modifiable lifestyle factors on the risk of childhood asthma and allergic conditions, only one previous small study conducted among 609 Puerto Rican children aged 6-14 years has assessed the potential synergistic effects of several risk factors (obesity, early-life secondhand smoking, unhealthy diet and gun violence exposure) on asthma risk. ${ }^{12}$

In this large study, we developed a Healthy Lifestyle Index (HLI) composed of five potentially modifiable lifestyle factorsparental smoking, child's adherence to Mediterranean diet, healthy body mass index (BMI), child's physical activity and sedentary behaviour-and examined the association of this index with risk of asthma, rhinoconjunctivitis and eczema symptoms using data from ISAAC phase III. We used this multidimensional lifestyle approach to estimate the impact of potential prevention strategies (mainly recommended for non-respiratory diseases) on the population burden of asthma, rhinitis and eczema in childhood.

\section{METHODS}

\section{Study participants}

ISAAC phase III 2000-2003 was a multicentre, multicountry, cross-sectional study of children (aged 6-7 years) and adolescents (aged 13-14 years) chosen from a random sample of schools in each defined geographical area. ${ }^{13}$ The present study is based on data for healthy lifestyle behaviour in 70795 children aged 6-7 years from 37 centres in 19 countries.

\section{Child's health outcomes assessment}

Information on symptoms of asthma, rhinoconjunctivitis and eczema was obtained from parents/guardians of the child through the ISAAC phase III core questionnaire (http://isaac. auckland.ac.nz). Current symptoms of asthma were indicated by current wheeze defined as a positive answer to the written question 'Has your child had wheezing or whistling in the chest in the past 12 months?'. Reported asthma ever was defined as a positive response to the question: 'Has your child ever had asthma?'.

Current symptoms of rhinoconjunctivitis were determined by positive answers to two questions: 'In the past 12 months, has your child had a problem with sneezing, or a runny or blocked nose when he/she did not have a cold or the influenza?' If yes, 'In the past 12 months, has this nose problem been accompanied by itchy-watery eyes?'. Hay fever ever was defined as an affirmative answer to the question 'Has your child ever had hay fever?'.

Current symptoms of eczema were determined by positive answers to: 'Has your child ever had an itchy rash which was coming and going for at least 6 months?' If yes, 'Has your child had this itchy rash at any time in the past 12 months?' If yes, 'Has this itchy rash at any time affected any of the following places: the folds of the elbows, behind the knees, in front of the ankles, under the buttocks or around the neck, ears or eyes?'. Reported eczema ever was determined by a positive answer to: 'Has your child ever had eczema?'.

\section{Assessment of lifestyle factors and derivation of the HLI}

Information on lifestyle factors was collected from parents/ guardians of the child using the ISAAC phase III environmental questionnaire (http://isaac.auckland.ac.nz). The following questions were used to assess smoking habits by the parents of children: (1) Does your child's mother (or female guardian) smoke cigarettes? and (2) Does your child's father (or male guardian) smoke cigarettes? Parents were also asked about the weight and height of their children, which was used to calculate the BMI in $\mathrm{kg} / \mathrm{m}^{2}$. Overweight and obesity were defined according to the cut-off points of child's BMI defined by Cole et al for each age group and sex ${ }^{14}$ which provides cut-off points for overweight $\left(25 \mathrm{~kg} / \mathrm{m}^{2}\right)$ and obesity $\left(30 \mathrm{~kg} / \mathrm{m}^{2}\right)$ from the age of 2 years and the projection of these values at the age of 18 years.

The environmental questionnaire also included questions about the frequency of consumption over the past year (never or occasionally, one or twice per week, three or more times a week) of the following foods: meat, seafood (including fish), fruit, vegetables, pulses, cereal, pasta, rice, butter, margarine, nuts, potatoes, milk, eggs and fast food/burgers. A score of the 'Mediterranean diet' pattern was developed according to the consumption frequency of these food items based on the score used by Psaltopoulou et al. ${ }^{15}$ Fruit, seafood, vegetables, pulses, cereal, pasta, rice and potatoes were considered 'pro-Mediterranean' foods and eating each of these foods was rated 0 (never or occasionally), 1 (one or twice per week) or 2 (three or more times a week) points. Meat, milk and fast food/burgers were considered 'anti-Mediterranean' foods and eating each of these was rated 0 (three or more times a week), 1 (one or twice per week) or 2 (never or occasionally) points. In contrast to the score by Psaltopoulou $e t a l,{ }^{15}$ the ISAAC questionnaire did not allow adjustment of food consumption to energy intake. The points for each of the 11 items were added up to a summary score.

The amount of exercise done by the child was assessed by the question: 'How many times a week does your child engage in vigorous physical activity long enough to make him/her breathe hard (never or occasionally, once or twice per week, three or more times per week)?'. Television viewing was assessed by the question: 'During a normal week, how many hours a day (24 hours) does your child watch television?'. Possible responses were less than an hour, 1 hour but less than 3 hour, 3 hour but less than 5 hour or 5 hour or more.

We then used a binary score for each evaluated factor to allow easy translation of findings into a potential policy context. Children were assigned one point for each of the following factors: mother and father both non-smokers, child has a healthy BMI, child undertakes vigorous physical activity (at least one time per week), child does not have a sedentary behaviour (less than 1 hour a week of television viewing) and adheres to a Mediterranean diet (Mediterranean diet score above the median value). Finally, the HLI was constructed by summing the binary score for each of the five modifiable lifestyle factors which ranged from 0 (least healthy) to 5 (most healthy) points.

\section{Statistical analysis}

Each centre included in the analysis had to assess at least 1000 children and have a response rate higher than $60 \%$. We used multilevel mixed-effects logistic regression to evaluate the effect of a HLI on the presence of asthma, rhinoconjunctivitis and eczema at age 6-7 years and calculated ORs and 95\% CIs. The HLI was modelled as a continuous and categorical variable with four categories ( 0 or 1 factor, 2 factors, 3 factors and 4 or 5 factors), using 0 or 1 factor as the reference category. In the main model, adjustment was performed for sex of the child, region of the world (Western Europe, Northern and Eastern Europe, Eastern Mediterranean, Latin America, Asia Pacific and Oceania) and per capita gross national income (GNI) (categorised by the World Bank as low, lower middle, upper middle and high). ${ }^{16}$ Centre was included in all models as a random intercept.

Multiple regression analyses investigated whether the associations between HLI and assessed health outcomes were confounded by other variables in the environmental 
questionnaire. Covariates in the multiple regression analyses were maternal education level (primary, secondary, or tertiary), ever breastfeeding (yes or no), siblings (yes or no), pets at home (yes or no) and paracetamol use for fever in the first year of life (yes or no). Covariates that were significantly associated with symptoms at $\mathrm{p}<0.05$ or changed the effect estimate $(\mathrm{OR}) \geq 10 \%$ were included in the final models. In multiple regression analyses, children who had a missing value for any of the covariates were removed. No imputation was done for missing data, as previous analyses had shown that little or no bias was introduced by limiting the multiple regression analyses to children with complete data. ${ }^{17}$

Stratified analyses were performed for child's sex, region of the world and GNI. In addition, a meta-analysis was performed to take into account the heterogeneity between the centres. Random effects models were used and heterogeneity among centres was tested by using the Cochran $\mathrm{Q}$ test with a significance level of 0.10 and quantified by using the $\mathrm{I}^{2}$ statistic.

To estimate the proportion or percentage of cases in the entire study population that could be prevented had all children been following four or all five healthy lifestyle factors (ie, lowest risk exposure group), we derived centre-specific population-attributable risk fractions (PARFs) (unadjusted for potential confounders) by comparing the total prevalence for each health outcome in that centre with the prevalence in the lowest risk exposure group $(\mathrm{PARF}=100 \% \times($ total prevalence - lowest risk group prevalence)/(total prevalence)). Analyses were performed using the statistical package Stata version 15.0.

\section{RESULTS}

The characteristics of the study participants are shown in table 1. Median age of participants was $6.6 \pm 0.5$ year, and $35122(49.6 \%)$ of them were male. A complete list of countries, number of centres and children per country, prevalence of current wheeze, reported asthma ever, rhinoconjunctivitis and eczema is shown in the online supplementary table S1. The healthy lifestyle components were distributed as follows: $57 \%$ of children had no exposure to maternal and paternal smoking during childhood, $74.1 \%$ of children had a healthy BMI, $41.1 \%$ of children adhered to a Mediterranean diet, $61.9 \%$ of children were physically active and $16.5 \%$ of children did not have a sedentary behaviour pattern (online supplementary table S2).

Children having a higher HLI score were more likely to be from Western Europe and Latin America, from countries with high GNI and were more likely to have mothers with higher educational level (table 2). Moreover, children having a higher HLI score were more likely to be male, ever breastfed, had more siblings and pets at home and a lower use of paracetamol for fever in the first year of life (table 2).

Compared with children with no or one healthy lifestyle factor, the multiple regression adjusted OR for current wheeze was 0.93 (95\% CI 0.87 to 1.01) for two factors, 0.77 (95\% CI 0.71 to 0.83 ) for three factors and 0.66 (95\% CI 0.60 to 0.72 ) for four or five factors; $p$-trend $<0.001$ (table 3 ). The decreased risk of reported asthma ever was similar to that for current symptoms of asthma. Estimates were similar in all children and in those with complete covariate data (table 3).

Compared with children with no or one healthy lifestyle factor, the multiple regression adjusted OR for current symptoms of rhinoconjunctivitis was 0.99 (95\% CI 0.91 to 1.07 ) for two factors, 0.92 (95\% CI 0.84 to 1.00$)$ for three factors and 0.86 (95\% CI 0.78 to 0.95 ) for four or five factors. No significant risk reduction was observed for hay fever ever. In addition,
Table 1 Healthy Lifestyle Index, child and family characteristics, International Study of Asthma and Allergies in Childhood phase III $(n=70795)$

\begin{tabular}{|c|c|}
\hline \multicolumn{2}{|l|}{ Healthy Lifestyle Index components } \\
\hline No parental smoking & $40357(57.0)$ \\
\hline Child's healthy body mass index & $52481(74.1)$ \\
\hline $\begin{array}{l}\text { Child's adherence to Mediterranean } \\
\text { diet }\end{array}$ & $29084(41.1)$ \\
\hline Child's physical activity & $43836(61.9)$ \\
\hline Child's no sedentary behaviour & $11691(16.5)$ \\
\hline \multicolumn{2}{|l|}{ Child's health outcomes } \\
\hline Current wheeze, yes & $7343(10.5)$ \\
\hline Missing data & 808 \\
\hline Asthma ever, yes & $6990(10.1)$ \\
\hline Missing data & 1426 \\
\hline Current symptoms of rhinoconjunctivitis & $6438(10.9)$ \\
\hline Missing data & 11704 \\
\hline Hay fever ever, yes & $7031(10.5)$ \\
\hline Missing data & 3965 \\
\hline Current symptoms of eczema & $5612(8.5)$ \\
\hline Missing data & 4648 \\
\hline Eczema ever, yes & 12352 (18.6) \\
\hline Missing data & 4288 \\
\hline \multicolumn{2}{|l|}{ Region of the world } \\
\hline Western Europe & $21002(29.6)$ \\
\hline Northern and Eastern Europe & $8478(12.0)$ \\
\hline Eastern Mediterranean & $9474(13.4)$ \\
\hline Latin America & $19825(28.0)$ \\
\hline Asia Pacific & $8615(12.2)$ \\
\hline Oceania & $3401(4.8)$ \\
\hline \multicolumn{2}{|l|}{ Gross national income } \\
\hline Low income & $1438(2.0)$ \\
\hline Low middle income & 11742 (16.6) \\
\hline Upper middle income & $28383(40.1)$ \\
\hline High income & $29232(41.3)$ \\
\hline \multicolumn{2}{|l|}{ Maternal education level } \\
\hline Primary & $13246(20.6)$ \\
\hline Secondary & $28390(44.1)$ \\
\hline Terciary & $22716(35.3)$ \\
\hline Missing data & 6443 \\
\hline \multicolumn{2}{|l|}{ Sex of the child } \\
\hline Male & $35122(49.6)$ \\
\hline Female & $35673(50.4)$ \\
\hline Child's age (years) & $6.6(0.5)$ \\
\hline Ever breastfed & $53496(79.7)$ \\
\hline Missing data & 3645 \\
\hline Siblings, yes & $54369(83.6)$ \\
\hline Missing data & 5803 \\
\hline Pets at home, yes & $23765(35.9)$ \\
\hline Missing data & 4663 \\
\hline Paracetamol use for fever, yes & $44464(64.9)$ \\
\hline Missing data & 2315 \\
\hline
\end{tabular}


Table 2 Characteristics of study participants by Healthy Lifestyle Index score, International Study of Asthma and Allergies in Childhood phase III

\begin{tabular}{|c|c|c|c|c|c|c|}
\hline & \multirow[b]{2}{*}{ All } & \multicolumn{4}{|c|}{ Healthy Lifestyle Index points } & \multirow[b]{2}{*}{$P$ value } \\
\hline & & 0 or 1 & 2 & 3 & 4 or 5 & \\
\hline Participants & 70795 & $11789(16.6)$ & $23565(33.3)$ & $23504(33.2)$ & $11937(16.9)$ & \\
\hline Current wheeze & 69987 & $1363(11.7)$ & $2643(11.4)$ & $2306(9.9)$ & $1031(8.7)$ & $<0.001$ \\
\hline Asthma ever & 69369 & 1199 (10.4) & $2336(10.1)$ & $2319(10.0)$ & $1136(9.7)$ & 0.303 \\
\hline Current symptoms of rhinoconjunctivitis & 59091 & $1072(11.1)$ & $2183(11.2)$ & $2150(10.8)$ & $1033(10.3)$ & 0.102 \\
\hline Hay fever ever & 66830 & $1131(10.2)$ & $2377(10.7)$ & $2353(10.6)$ & $1170(10.4)$ & 0.542 \\
\hline Current symptoms of eczema & 66147 & $976(8.9)$ & $1846(8.4)$ & $1863(8.4)$ & $927(8.2)$ & 0.200 \\
\hline Eczema ever & 66507 & $1942(17.7)$ & $4035(18.3)$ & $4008(18.1)$ & $2367(20.9)$ & $<0.001$ \\
\hline \multicolumn{7}{|l|}{ Region of the world } \\
\hline Western Europe & 70795 & $2916(24.7)$ & $6594(28.0)$ & $7104(30.2)$ & $4388(36.8)$ & $<0.001$ \\
\hline Northern and Eastern Europe & & 1939 (16.5) & 2958 (12.6) & $2437(10.4)$ & $1144(9.6)$ & \\
\hline Eastern Mediterranean & & $1624(13.8)$ & 3409 (14.5) & $3112(13.2)$ & $1329(11.1)$ & \\
\hline Latin America & & $3320(28.2)$ & $6632(28.1)$ & $6895(29.3)$ & $2978(24.9)$ & \\
\hline Asia Pacific & & $1668(14.1)$ & $3062(13.0)$ & $2609(11.1)$ & $1276(10.7)$ & \\
\hline Oceania & & $322(2.7)$ & $910(3.9)$ & $1347(5.7)$ & $822(6.9)$ & \\
\hline \multicolumn{7}{|l|}{ Gross national income per capita } \\
\hline Low income & 70795 & $57(0.50)$ & $353(1.50)$ & $630(2.7)$ & $398(3.3)$ & $<0.001$ \\
\hline Low middle income & & $2456(20.8)$ & $4580(19.4)$ & $3582(15.2)$ & $1124(9.4)$ & \\
\hline Upper middle income & & $5144(43.6)$ & $9534(40.5)$ & 9318 (39.6) & $4387(36.8)$ & \\
\hline High income & & $4132(35.1)$ & 9098 (38.6) & $9974(42.4)$ & $6028(50.5)$ & \\
\hline Child's sex, male & 70795 & $5672(48.1)$ & $11535(48.9)$ & $11912(50.7)$ & $6003(50.3)$ & $<0.001$ \\
\hline \multicolumn{7}{|l|}{ Maternal education level } \\
\hline Primary & 64352 & $2806(25.6)$ & $4681(21.8)$ & $4077(19.2)$ & $1682(15.8)$ & $<0.001$ \\
\hline Secondary & & $5077(46.4)$ & $9841(45.8)$ & $9286(43.7)$ & $4186(39.3)$ & \\
\hline Terciary & & 3055 (27.9) & $6987(32.5)$ & $7889(37.1)$ & 4785 (44.9) & \\
\hline Ever breastfed & 67150 & $8411(76.3)$ & $17494(78.7)$ & $18075(80.7)$ & $9516(82.8)$ & $<0.001$ \\
\hline Siblings, yes & 64992 & $8781(80.9)$ & $17904(82.8)$ & $18300(84.8)$ & $9384(85.8)$ & $<0.001$ \\
\hline Pets at home & 66132 & 4419 (39.3) & $8106(36.5)$ & 7630 (34.9) & $3610(33.2)$ & $<0.001$ \\
\hline Paracetamol use for fever & 68480 & $7562(66.6)$ & $15054(66.2)$ & $14634(64.3)$ & $7214(62.2)$ & $<0.001$ \\
\hline
\end{tabular}

Data are $\mathrm{n}(\%)$. P value derived from $\chi^{2}$ test.

compared with children with no or one healthy lifestyle factor, a reduced risk of current symptoms of eczema was found among children with two factors (adjusted OR 0.89 , 95\% CI 0.81 to 0.98 ), three factors (adjusted OR $0.84,95 \%$ CI 0.75 to 0.94 ) and four or five factors (adjusted OR $0.84,95 \%$ CI 0.75 to 0.94). No association was found for eczema ever.

The OR estimates were essentially the same after stratification by child's sex (online supplementary table S3). When stratified by region of the world, the decreased risk of current wheeze, current symptoms of rhinoconjunctivitis and eczema associated with a higher HLI was primarily observed among children of Western Europe and Latin America (online supplementary table S4). Stratified analyses by GNI showed that the reduced risk of current wheeze, current symptoms of rhinoconjunctivitis and eczema in relation to higher HLI was observed among regions with upper middle and high incomes (online supplementary table S5).

When conducting meta-analyses in order to evaluate centre-specific effects, the results obtained were nearly identical to those obtained in the pooled analyses (figures 1 and 2). A one-point increase in the HLI score was associated with a decreased risk of current wheeze (adjusted OR 0.87, 95\% CI 0.84 to 0.91 ), reported asthma ever (adjusted OR 0.89, 95\% CI
0.86 to 0.92 ), current symptoms of rhinoconjunctivitis (adjusted OR $0.96,95 \%$ CI 0.92 to 1.01 ) and current symptoms of eczema (adjusted OR 0.95 , 95\% CI 0.91 to 0.99 ). However, significant heterogeneity was detected between centres.

Table 4 shows the PARFs estimated for the lowest-risk HLI group for each assessed health outcome. Overall, the percentages of preventable cases of current symptoms of asthma, reported asthma ever, current symptoms of rhinoconjunctivitsis and current symptoms of eczema attributable to adherence to a combination of 4-5 of these healthy lifestyle factors were $20 \%$, $16 \%, 6 \%$ and 5\%, respectively. Overall, stronger PARFs were found among Western Europe and Latin American children.

\section{DISCUSSION}

This large worldwide multicentre cross-sectional study found that in children aged 6-7 years, an index based on five potentially modifiable lifestyle factors (ie, no parental smoking, child's healthy body mass index, adherence to a Mediterranean diet, physical activity and non-sedentary behaviour) was inversely associated with risk of asthma, rhinoconjunctivitis and eczema symptoms. The associations were stronger among children from Western Europe and Latin America and from 
Table 3 Associations* (OR and 95\% Cl) between Healthy Lifestyle Index and symptoms of asthma, rhinoconjunctivitis and eczema at 6-7 years of age, International Study of Asthma and Allergies in Childhood phase III

\begin{tabular}{|c|c|c|c|c|c|c|c|}
\hline & \multirow[b]{2}{*}{$\mathrm{N}$} & \multicolumn{5}{|c|}{ Healthy Lifestyle Index points } & \multirow{2}{*}{$\begin{array}{l}\text { Per one-point } \\
\text { increase }\end{array}$} \\
\hline & & $0-1$ & 2 & 3 & $4-5$ & $P$ trend & \\
\hline \multicolumn{8}{|c|}{ Current wheeze } \\
\hline Unadjusted & 69987 & 1 & 0.95 (0.89 to 1.02$)$ & 0.79 (0.73 to 0.85$)$ & 0.67 (0.62 to 0.73 ) & $<0.001$ & $0.88(0.86$ to 0.90$)$ \\
\hline Adjustedt & 69987 & 1 & 0.95 (0.88 to 1.02$)$ & 0.78 (0.73 to 0.84$)$ & $0.67(0.61$ to 0.73$)$ & $<0.001$ & 0.88 (0.86 to 0.90$)$ \\
\hline Adjusted $\ddagger$ & 61122 & 1 & 0.93 (0.86 to 1.00$)$ & 0.76 (0.70 to 0.82$)$ & 0.63 (0.58 to 0.70$)$ & $<0.001$ & 0.86 (0.84 to 0.89$)$ \\
\hline Adjusted§ & 61122 & 1 & 0.93 (0.87 to 1.01$)$ & 0.77 (0.71 to 0.83 ) & 0.66 (0.60 to 0.72 ) & $<0.001$ & $0.87(0.85$ to 0.89$)$ \\
\hline \multicolumn{8}{|l|}{ Asthma ever } \\
\hline Unadjusted & 69369 & 1 & 0.92 (0.85 to 0.99$)$ & $0.83(0.77$ to 0.90$)$ & 0.73 (0.67 to 0.80$)$ & $<0.001$ & 0.91 (0.89 to 0.93$)$ \\
\hline Adjustedt & 69369 & 1 & 0.91 (0.84 to 0.98$)$ & 0.82 (0.76 to 0.89 ) & 0.72 (0.66 to 0.79 ) & $<0.001$ & 0.91 (0.88 to 0.93$)$ \\
\hline Adjusted $\ddagger$ & 55494 & 1 & 0.88 (0.81 to 0.96$)$ & 0.77 (0.70 to 0.84$)$ & 0.64 (0.58 to 0.71 ) & $<0.001$ & $0.88(0.85$ to 0.90$)$ \\
\hline Adjustedף & 55494 & 1 & 0.89 (0.81 to 0.97$)$ & $0.79(0.72$ to 0.86$)$ & $0.67(0.60$ to 0.74$)$ & $<0.001$ & 0.89 (0.86 to 0.92$)$ \\
\hline \multicolumn{8}{|c|}{ Current symptoms of rhinoconjunctivitis } \\
\hline Unadjusted & 59091 & 1 & 0.98 (0.91 to 1.07$)$ & 0.91 (0.84 to 0.99 ) & 0.86 (0.79 to 0.95$)$ & $<0.001$ & 0.96 (0.93 to 0.98$)$ \\
\hline Adjustedt & 59091 & 1 & 0.98 (0.91 to 1.06$)$ & 0.91 (0.84 to 0.98$)$ & 0.86 (0.78 to 0.94$)$ & $<0.001$ & 0.95 (0.93 to 0.98$)$ \\
\hline Adjusted $\ddagger$ & 53366 & 1 & 0.98 (0.90 to 1.07$)$ & 0.90 (0.83 to 0.98 ) & 0.84 (0.76 to 0.92 ) & $<0.001$ & 0.95 (0.92 to 0.97$)$ \\
\hline Adjusted** & 53366 & 1 & 0.99 (0.91 to 1.07$)$ & 0.92 (0.84 to 1.00$)$ & 0.86 (0.78 to 0.95$)$ & 0.001 & 0.96 (0.93 to 0.98$)$ \\
\hline \multicolumn{8}{|c|}{ Hay fever ever } \\
\hline Unadjusted & 66830 & 1 & 1.03 (0.95 to 1.11$)$ & 1.00 (0.92 to 1.08$)$ & 0.96 (0.87 to 1.05 ) & 0.189 & $0.98(0.96$ to 1.01$)$ \\
\hline Adjustedt & 66830 & 1 & 1.02 (0.95 to 1.11$)$ & 0.99 (0.91 to 1.07$)$ & 0.95 (0.87 to 1.04$)$ & 0.140 & 0.98 (0.96 to 1.01$)$ \\
\hline Adjusted $\ddagger$ & 53747 & 1 & 1.03 (0.95 to 1.13$)$ & 0.99 (0.90 to 1.08$)$ & 0.93 (0.83 to 1.03 ) & 0.060 & $0.97(0.95$ to 1.00$)$ \\
\hline Adjustedt† & 53747 & 1 & 1.03 (0.94 to 1.13$)$ & 0.99 (0.90 to 1.08$)$ & 0.92 (0.83 to 1.02 ) & 0.049 & $0.97(0.94$ to 1.00$)$ \\
\hline \multicolumn{8}{|c|}{ Current symptoms of eczema } \\
\hline Unadjusted & 66147 & 1 & 0.91 (0.84 to 0.99 ) & 0.89 (0.82 to 0.96$)$ & 0.86 (0.78 to 0.94 ) & 0.002 & 0.96 (0.93 to 0.99$)$ \\
\hline Adjustedt & 66147 & 1 & 0.91 (0.84 to 0.99 ) & 0.89 (0.82 to 0.97 ) & 0.86 (0.78 to 0.95$)$ & 0.003 & 0.96 (0.94 to 0.99$)$ \\
\hline Adjusted $\ddagger$ & 52689 & 1 & 0.90 (0.82 to 0.99$)$ & 0.87 (0.79 to 0.96$)$ & 0.86 (0.77 to 0.96$)$ & 0.005 & 0.96 (0.93 to 0.99$)$ \\
\hline Adjustedt† & 52689 & 1 & 0.89 (0.81 to 0.98$)$ & 0.86 (0.78 to 0.95$)$ & 0.84 (0.75 to 0.94$)$ & 0.002 & 0.96 (0.93 to 0.99$)$ \\
\hline \multicolumn{8}{|l|}{ Eczema ever } \\
\hline Unadjusted & 66507 & 1 & 1.01 (0.95 to 1.08$)$ & 0.99 (0.93 to 1.06$)$ & 1.10 (1.02 to 1.18$)$ & 0.039 & $1.03(1.01$ to 1.05$)$ \\
\hline Adjusted $t$ & 66507 & 1 & 1.01 (0.95 to 1.08 ) & 0.99 (0.93 to 1.06$)$ & 1.10 (1.02 to 1.18$)$ & 0.041 & 1.03 (1.01 to 1.05$)$ \\
\hline Adjusted $¥$ & 58164 & 1 & 1.02 (0.95 to 1.09 ) & 1.02 (0.96 to 1.10$)$ & 1.15 (1.07 to 1.25$)$ & $<0.001$ & $1.04(1.02$ to 1.07$)$ \\
\hline Adjusted & 58164 & 1 & 0.98 (0.92 to 1.05$)$ & 0.97 (0.90 to 1.04$)$ & 1.05 (0.97 to 1.13 ) & 0.346 & 1.01 (0.99 to 1.04$)$ \\
\hline
\end{tabular}

${ }^{*}$ Mixed-effects logistic regression including a random intercept for centre.

tAdjusted for child's sex, per capita GNI and region of the world.

¥Children with complete covariate data, adjusted for child's sex, GNI and region of the world.

§Multivariate analysis (children with complete covariate data), adjusted for child's sex, gross national income, region of the world, breastfeeding, pets at home and paracetamol use for fever in the first year.

१Multivariate analysis (children with complete covariate data), adjusted for child's sex, GNI, region of the world, maternal education, siblings, pets at home and paracetamol use for fever in the first year.

${ }^{* *}$ Multivariable analysis (children with complete covariate data), adjusted for child's sex, GNI, region of the world, pets at home and paracetamol use for fever in the first year. t†Multivariable analysis (children with complete covariate data), adjusted for child's sex, GNI, region of the world, maternal education, breastfeeding, siblings and paracetamol use for fever in the first year.

¥¥Multivariable analysis (children with complete covariate data), adjusted for child's sex, GNI, region of the world, maternal education, breastfeeding and paracetamol use for fever in the first year.

GNI, gross national income.

regions with upper-middle and higher GNIs. Theoretically, if these associations were causal, $20 \%$ of current wheeze and $16 \%$ of reported asthma ever cases would have been prevented had all children adhered to four or all five healthy lifestyle factors.

In the development and promotion of policies for disease prevention, the importance of the joint impact of modifiable lifestyle factors on lifespan, ${ }^{18}$ mortality, ${ }^{19}$ and chronic diseases such as cancer, ${ }^{20}{ }^{21}$ cardiovascular disease, ${ }^{22}$ and diabetes has been extensively investigated and recognised. In contrast, the combined effects of recommended lifestyle changes on respiratory and allergic diseases in childhood has been rarely studied and infrequently recognised. This is the only large study, to our knowledge, examining the combined effect of five modifiable lifestyle risk factors on asthma and allergic diseases in childhood, providing novel evidence relevant to public health strategies which have been developed mainly to prevent non-respiratory disease in adults. 
A)

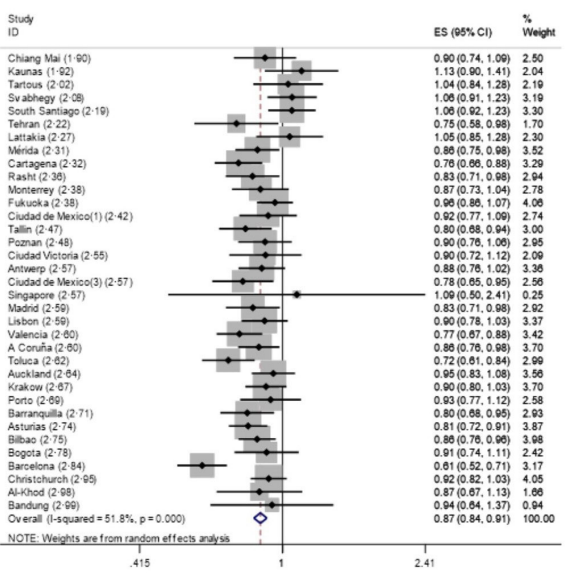

B)

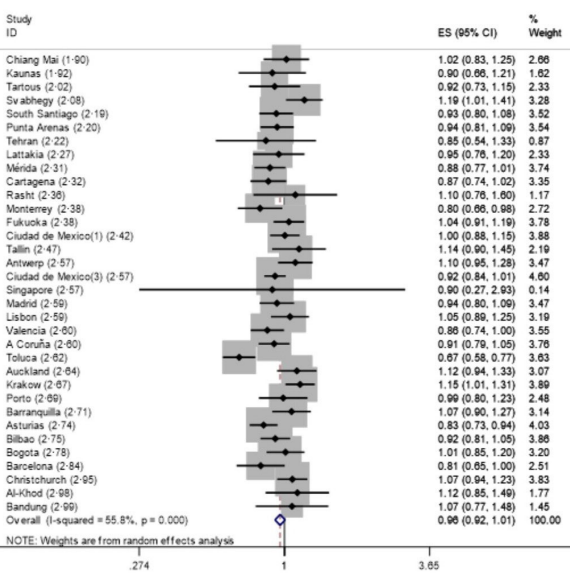

C)

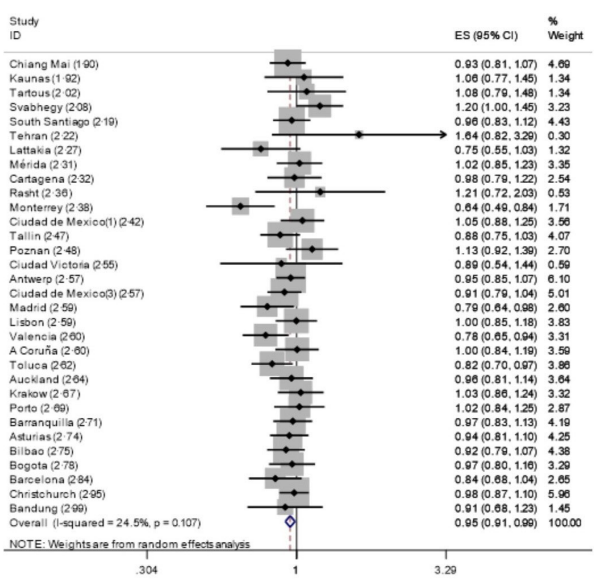

Figure 1 Associations* (OR and 95\% Cl) between 1-point increase in Healthy Lifestyle Index (HLI) during (A) childhood and current wheezet, (B) current symptoms of rhino-conjunctivitisł and (C) current symptoms of eczema§, International Study of Asthma and Allergies in Childhood phase III. *Centre-specific ORs and 95\% Cls from meta-analysis using random effects. For each centre, the mean HLI score is stated in brackets. †Models adjusted for child's sex, breastfeeding, pets at home and paracetamol use for fever in the first year. Punta Arenas and Caracas centres not included because of incomplete data. ¥Models adjusted for child's sex, pets at home, and paracetamol use for fever in the first year. Poznan, Ciudad Victoria and Caracas centres not included because of incomplete data. §Models adjusted for child's sex, maternal education level, breastfeeding, siblings and paracetamol use for fever in the first year. Punta Arenas, Caracas, Fukuoka, Singapore and Al-Khod centres not included because of incomplete data.

Our findings add strong evidence to the only previously published study that investigated the association between childhood asthma and a combination of several adverse lifestyle factors. ${ }^{12}$ This small case-control study conducted among 609 Puerto Rican children aged 6-14 years showed that the presence of three risk factors compared with none was associated with 10 -fold to 11-fold increased odds of asthma. Furthermore, our results for children are in agreement with a study of adults aged 18-44 years that assessed the combined effects of BMI, smoking, drinking and solid fuel use on wheezing symptoms and asthma and showed that in combination these were associated with double or triple the risk of asthma. ${ }^{23}$
When interpreting PARFs, it should be taken into account that these measures rely on the distribution of lifestyle factors among participants in the present study population. In this sense, lack of information from some countries may influence representativeness of some regions of the world. Furthermore, PARFs assume that the exposures are causal and unbiased, but studies with observational design are not sufficiently able to prove this assumption. Nevertheless, this knowledge may still be useful for tailoring interventions for lifestyle modification at target population subgroups.

The strengths of this multicentre study include its power, size and multinational nature. The study participants comprised
A)

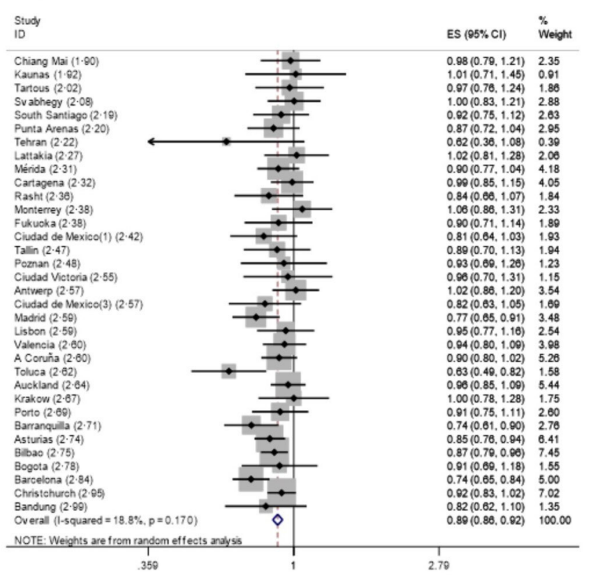

B)

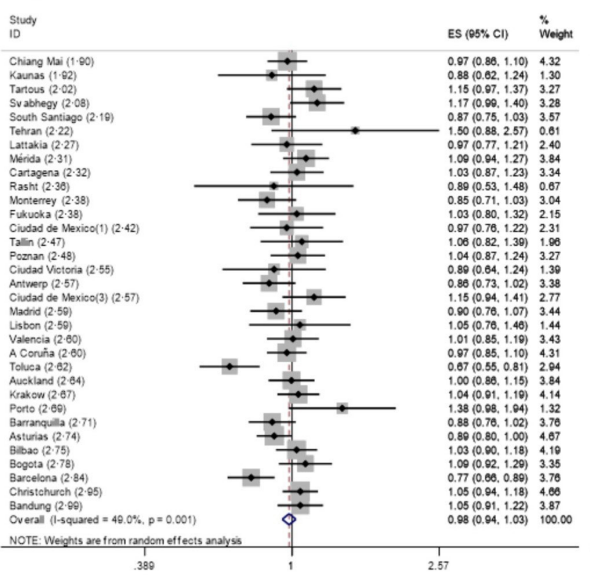

C)

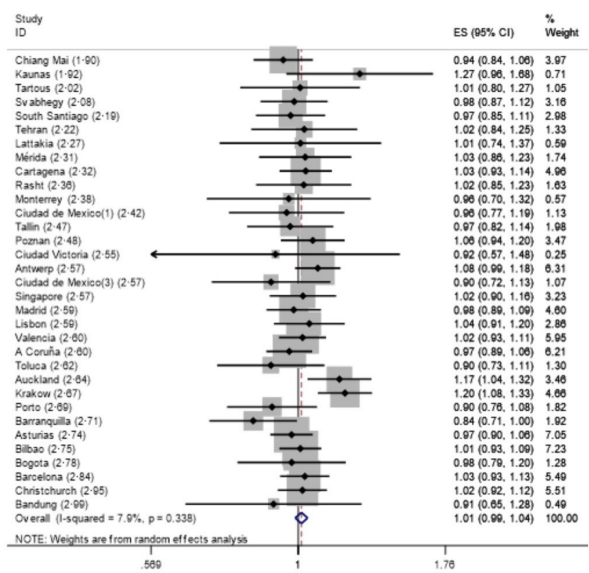

Figure 2 Associations* (OR and 95\% Cl) between one-point increase in Healthy Lifestyle Index (HLI) during (A) childhood and asthma evert, (B) hay fever ever $\ddagger$ and $(C)$ ever eczema§ in children aged 6-7 years, the International Study of Asthma and Allergies in Childhood phase III. *Centrespecific ORs and $95 \%$ Cls from meta-analysis using random effects. For each centre, the mean HLI score is stated in brackets. †Models adjusted for child's sex, maternal education level, siblings, pets at home and paracetamol use for fever in the first year. Singapore, Al-Khod and Caracas centres not included because of incomplete data. ¥Models adjusted for child’s sex, maternal education level, breastfeeding, siblings and paracetamol use for fever in the first year. Punta Arenas, Caracas, Singapore and Al-Khod centres not included because of incomplete data. §Models adjusted for child's sex, maternal education level, breastfeeding and paracetamol use for fever in the first year. Punta Arenas, Caracas, Fukuoka and Al-Khod centres not included because of incomplete data. 
Table 4 Population attributable risk fractions* for four or five Healthy Lifestyle Index factors, International Study of Asthma and Allergies in Childhood phase III

\begin{tabular}{|c|c|c|c|c|}
\hline & Current wheeze & Asthma ever & $\begin{array}{l}\text { Current symptoms of } \\
\text { rhinoconjunctivitis }\end{array}$ & $\begin{array}{c}\text { Current symptoms of } \\
\text { eczema }\end{array}$ \\
\hline All regions & 20.2 (12.8 to 27.6$)$ & 16.4 (10.2 to 22.6$)$ & $6.0(-2.8$ to 14.8$)$ & 4.8 (0.2 to 9.3$)$ \\
\hline \multicolumn{5}{|l|}{ Regions of the world } \\
\hline Western Europe & 25.5 (18.5 to 32.6$)$ & $16.4(7.4$ to 25.3$)$ & $10.8(2.3$ to 19.3$)$ & $3.1(-2.6$ to 8.9$)$ \\
\hline Northern and Eastern Europe & $10.5(-7.5$ to 28.6$)$ & $26.3(6.8$ to 45.7$)$ & $-20.2(-33.5$ to -6.9$)$ & $-7.0(-20.1$ to 6.1$)$ \\
\hline Eastern Mediterranean & $8.3(-25.9$ to 42.6$)$ & $2.7(-29.5$ to 34.9$)$ & $-7.8(-49.8$ to 34.2$)$ & $-0.9(-54.9$ to 53.1$)$ \\
\hline Latin America & $25.8(4.0$ to 47.5$)$ & $17.6(0.3$ to 35.0$)$ & $17.7(-1.1$ to 36.5$)$ & $11.8(-0.2$ to 23.8$)$ \\
\hline Asia Pacific & $16.6(-1.1$ to 34.4$)$ & $19.8(-8.9$ to 48.5$)$ & $11.6(-2.7$ to 25.9$)$ & $15.5(-4.5$ to 35.4$)$ \\
\hline Oceania & $6.58(-0.08$ to 13.2$)$ & 10.2 (4.8 to 15.6$)$ & $-15.9(-53.6$ to 21.8$)$ & $2.8(-4.5$ to 10.1$)$ \\
\hline
\end{tabular}

${ }^{*}$ Data represents the proportion $(95 \% \mathrm{Cls})$ of the cases attributable to not being in the lowest risk exposure group (ie, four or five healthy lifestyle factors). Negative values indicate no benefit from Healthy Lifestyle Index.

37 centres from 19 countries with diverse lifestyle patterns and a wide range of disease prevalence. Results obtained from meta-analyses of associations analysed within each study centre were essentially the same than those obtained from the pooled analyses, with little attenuated adjustment for possible confounding variables and clear dose-response relationship, which supports the consistency of present results.

Limitations of this study should also be considered. First, in order to construct the HLI, we dichotomised each lifestyle factor according to predefined cut-off points. Different threshold values would have resulted in different risk estimates. The choice of cut-off points was mostly based on public health recommendations and was generalised rather than risk specific. The likely influence of the dichotomisation of the variables in the index is underestimating the true effect of the observed associations. Measurement error in self-reported variables cannot be ruled out; however, such error would likely lead to a non-differential bias potentially leading to underestimating the true effects. We used a simplified diet quality index that may not sufficiently account for the complexity of diets. Second, reverse causation cannot be ruled out because of the cross-sectional design of the study (eg, asthma could reduce vigorous physical exercise and increase sedentary behaviour or allergic symptoms could modify some dietary patterns). Third, we relied on parental report for both the outcomes and the lifestyle factors; however, recognition of symptoms of asthma, rhinoconjunctivitis and eczema in children was based on validated symptom-based written questionnaires. ${ }^{1324}$ Fourth, information on lifestyle factors was obtained retrospectively, which may be subject to under-reporting, recall and reporting bias, which could have either attenuated or accentuated the observed associations. Finally, selection bias is also a potential limitation. It is probable that parents who did not respond to the ISAAC questionnaire differed in terms of their family lifestyle from those who did respond, but we consider it less likely that the strength of the association between the HLI and asthma or allergic disease among children would be seriously affected by this type of selection bias.

In summary, these findings emphasise the potential importance of the combined impact of modifiable lifestyle factors as preventable influences on childhood asthma and related allergic conditions. Results suggest that public health interventions which are commonly justified for prevention of cardiovascular disease and cancer are unlikely to jeopardise asthma prevention and may be required if the burden of common allergic diseases in childhood is to be reduced. However, our findings should be interpreted with caution given the limitations to infer causality from cross-sectional observational data. Randomised controlled trials evaluating the impact of strategies for prevention of asthma in childhood should include interventions on multiple modifiable lifestyle factors to provide sufficient evidence of their efficacy to lead to widespread implementation for public health primary prevention.

Acknowledgements The authors acknowledge the funders who supported the ISAAC International Data Centre listed elsewhere.

Collaborators Steering committee-N Ait-Khaled* (Union Internationale Contre la Tuberculose et les Maladies Respiratoires, Paris, France); H R Anderson (Department of Public Health Sciences, St George's Hospital Medical School, London, UK); M I Asher (Department of Paediatrics, Faculty of Medical and Health Sciences, University of Auckland, New Zealand); R Beasley* (Medical Research Institute of New Zealand, Wellington, New Zealand); B Björkstén* (Institute of Environmental Medicine, Karolinska Institutet, Stockholm, Sweden); B Brunekreef (Institute of Risk Assessment Science, Universiteit Utrecht, Netherlands); I Crane (Wellington Asthma Research Group, Wellington School of Medicine, New Zealand); P Ellwood (Department of Paediatrics, Faculty of Medical and Health Sciences, University of Auckland, New Zealand); L García-Marcos (Instituto de Salud Respiratoria, Universidad de Murcia, Spain); S Foliaki* (Centre for Public Health Research, Massey University, Wellington, New Zealand); U Keil* (Institut für Epidemiologie und Sozialmedizin, Universität Münster, Germany); C K W Lai* (Department of Medicine and Therapeutics, The Chinese University of Hong Kong, SAR China); J Mallol* (Department of Respiratory Medicine, University of Santiago de Chile, Chile); C F Robertson (Department of Respiratory Medicine, Royal Children's Hospital, Parkville, Australia); E A Mitchell (Department of Paediatrics, Faculty of Medical and Health Sciences, University of Auckland, New Zealand); S Montefort* (Department of Medicine, University of Malta, Malta), J Odhiambo* + (Centre Respiratory Diseases Research Unit, Kenya Medical Research Institute, Nairobi, Kenya); N Pearce (Centre for Public Health Research, Massey University, Wellington, New Zealand); J Shah* (Jaslok Hospital and Research Centre, Mumbai, India); A W Stewart (Population Health, Faculty of Medical and Health Sciences, University of Auckland, New Zealand); D Strachan (Department of Public Health Sciences, St Georges Hospital Medical School, London, UK); E von Mutius (Dr von Haunerschen Kinderklinik de Universität München, Germany); S K Weilandt (Department of Epidemiology, University of Ulm, Germany); G Weinmayr (Institute of Epidemiology, University of Ulm, Germany); H Williams (Centre for Evidence Based Dermatology, Queen's Medical Centre, University Hospital, Nottingham, UK); G Wong (Department of Paediatrics, Prince of Wales Hospital, Hong Kong, SAR China) (*Regional coordinators tdeceased). ISAAC International Data Centre: M I Asher, T O Claytont, P Ellwood, E A Mitchell (Department of Paediatrics, University of Auckland, New Zealand); and A W Stewart (School of Population Health, Faculty of Medical and Health Sciences, University of Auckland, New Zealand) (tdeceased). ISAAC principal investigators: Belgium-J Weyler; Chile—L Amarales, P Aguilar; Colombia_A M Cepeda, G Aristizábal; Estonia-M-A Riikjärv; Hungary—G Zsigmond; Indonesia-C B Kartasasmita; Iran-M-R Masjedi; Japan-H Odajima; Lithuania—J Kudzyte; Mexico-B E Del-Río-Navarro, M Barragán-Meijueiro, R García-Almaraz, M Baeza-Bacab, S N González-Díaz, F J Linares-Zapién; New Zealand-M I Asher, P Pattemore; Oman-0 Al-Rawas; Poland —G Lis, A Brêborowicz; Portugal—J E Rosado Pinto, J M Lopes dos Santos; Singapore-D Y T Goh; Spain—A López-Silvarrey Varela, I Carvajal-Urueña, R M Busquets, C González Díaz, L García-Marcos, G Garcia-Hernández, M M M Suárez-Varela; Syrian Arab Republic —Y Mohammad, S Mohammad; Thailand— M Trakultivakorn; Venezuela—o Aldrey. 
Contributors EM and LGM conceived the study. EM and DS conducted the statistical analyses. EM, DS and LGM prepared the first draft. All other authors provided data, reviewed results and reviewed and contributed to the article.

Funding EM was funded by a Miguel Servet Grant Fellowship (MS14/00046) awarded by the Spanish Instituto de Salud Carlos III (ISCIII), Ministry of Economy and Competitiveness and Fondos FEDER.

Competing interests None declared.

Patient consent for publication Guardian consent obtained.

Provenance and peer review Not commissioned; externally peer reviewed.

\section{REFERENCES}

1 The Global Asthma. Report 2014. Auckland, New Zealand: Global Asthma Network, 2014.

2 Pearce N, Ait-Khaled N, Beasley R, et al. Worldwide trends in the prevalence of asthma symptoms: phase III of the International study of asthma and allergies in childhood (Isaac). Thorax 2007;62:758-66.

3 The Global Asthma. Report 2018. Auckland, New Zealand: Global Asthma Network, 2018

4 Eder W, Ege MJ, von Mutius E. The asthma epidemic. N Eng/ J Med 2006;355:2226-35.

5 Beasley R, Semprini A, Mitchell EA. Risk factors for asthma: is prevention possible? Lancet 2015;386:1075-85.

6 Mitchell EA, Beasley R, Keil U, et al. The association between tobacco and the risk of asthma, rhinoconjunctivitis and eczema in children and adolescents: analyses from phase three of the Isaac programme. Thorax 2012:67:941-9.

7 Nagel G, Weinmayr G, Kleiner A, et al. Effect of diet on asthma and allergic sensitisation in the International study on allergies and asthma in childhood (Isaac) phase two. Thorax 2010;65:516-22.

8 Ellwood P. Asher Ml, García-Marcos L, et al. Do fast foods cause asthma, rhinoconjunctivitis and eczema? global findings from the International study of asthma and allergies in childhood (Isaac) phase three. Thorax 2013;68:351-60.

9 Castro-Rodriguez JA, Garcia-Marcos L. What are the effects of a Mediterranean diet on allergies and asthma in children? Front Pediatr 2017;5.

10 Weinmayr G, Forastiere F, Büchele G, et al. Overweight/obesity and respiratory and allergic disease in children: International study of asthma and allergies in childhood (Isaac) phase two. PLoS One 2014;9:e113996.

11 Mitchell EA, Beasley R, Björkstén B, et al. The association between BMI, vigorous physical activity and television viewing and the risk of symptoms of asthma, rhinoconjunctivitis and eczema in children and adolescents: Isaac phase three. Clin Exp Allergy 2013;43:73-84.

12 Szentpetery SS, Gruzieva O, Forno E, et al. Combined effects of multiple risk factors on asthma in school-aged children. Respir Med 2017;133:16-21.

13 Ellwood P, Asher MI, Beasley R, et al. The International study of asthma and allergies in childhood (Isaac): phase three rationale and methods. Int I Tuberc Lung Dis 2005;9:10-16.

14 Cole TJ, Bellizzi MC, Flegal KM, et al. Establishing a standard definition for child overweight and obesity worldwide: international survey. BMJ 2000;320:1240-3.

15 Psaltopoulou T, Naska A, Orfanos P, et al. Olive oil, the Mediterranean diet, and arterial blood pressure: the Greek European Prospective investigation into cancer and nutrition (EPIC) study. Am J Clin Nutr 2004;80:1012-8.

16 The World Bank Group. World bank atlas method. Available: http://econ.worldbank. org [Accessed 5 Oct 2005].

17 Beasley R, Clayton T, Crane J, et al. Association between paracetamol use in infancy and childhood, and risk of asthma, rhinoconjunctivitis, and eczema in children aged 6-7 years: analysis from phase three of the Isaac programme. Lancet 2008;372:1039-48.

18 Larsson SC, Kaluza J, Wolk A. Combined impact of healthy lifestyle factors on lifespan: two prospective cohorts. J Intern Med 2017;282:209-19.

19 Veronese N, Li Y, Manson JE, et al. Combined associations of body weight and lifestyle factors with all cause and cause specific mortality in men and women: prospective cohort study. BMJ 2016;355.

20 Aleksandrova K, Pischon T, Jenab M, et al. Combined impact of healthy lifestyle factors on colorectal cancer: a large European cohort study. BMC Med 2014;12.

21 McKenzie F, Ferrari P, Freisling H, et al. Healthy lifestyle and risk of breast cancer among postmenopausal women in the European Prospective investigation into cancer and Nutrition cohort study. Int J Cancer 2015;136:2640-8.

22 Meyer U, Schindler C, Bloesch T, et al. Combined impact of negative lifestyle factors on cardiovascular risk in children: a randomized prospective study. J Adolesc Health 2014;55:790-5.

23 Patra J, Maher YI, Mishra S, et al. Effects of body mass index, tobacco smoking, alcohol drinking and solid fuel use on the risk of asthma: Individual Participant Data (IPD) meta-analysis of 175000 individuals from 51 nationally representative surveys. BMJ Open Respir Res 2016;3:e000121.

24 Asher Ml, Montefort S, Björkstén B, et al. Worldwide time trends in the prevalence of symptoms of asthma, allergic rhinoconjunctivitis, and eczema in childhood: Isaac phases one and three repeat multicountry cross-sectional surveys. Lancet 2006:368:733-43. 